\title{
NOWCASTING REAL GDP FOR SAUDI ARABIA*
}

November 2020

By

Ryadh M. Alkhareif

International Monetary Fund, and

\author{
William A. Barnett \\ University of Kansas, and \\ Center for Financial Stability, USA
} Saudi Arabia's Ministry of Finance

\footnotetext{
* Main author contact information: Ryadh Alkhareif, International Monetary Fund (IMF).
}

Email: r.alkhareif@mof.gov.sa and ralkhareif@imf.org. 


\title{
NOWCASTING REAL GDP FOR SAUDI ARABIA
}

\begin{abstract}
The paper constructs monthly GDP nowcasts for Saudi Arabia by estimating a Generalized Dynamic Factor Model (GDFM) on a panel of 272 variables over the period from January 2010 to June 2018. The GDP nowcasts produced in this paper can accurately mimic GDP growth rates for Saudi Arabia, including for the non-oil sector. Our GDFM has outperformed other traditional models in tracking the business cycle in Saudi Arabia. In our view, the non-oil private sector GDP nowcasts provided in this paper can substitute the traditional set of indicators used to monitor monthly private sector activity.
\end{abstract}

Keywords: Nowcast, non-oil GDP, generalized dynamic factor model, principal components analysis.

JEL Classifications: C22, E53, E37

\section{Introduction}

Measuring the current state of the economy is a key objective for policymakers and investors alike, including in Saudi Arabia where bold economic and social reforms are proceeding at a rapid pace. In order to assess the current state of the economy, policymakers and investors rely on indicators that are published with lags and subject to substantial revisions. In particular, there are two major issues facing policymakers and investors when using economic indicators: timeliness and noisiness. The issue of timeliness of data arises when key variables such as GDP are published with delays and only available with low 
frequency. On the noisiness issue, data often contain some noise and other measurement issues that could possibly lead to misjudgment about the current state of the economy. This is evident from the noticeable revisions of GDP data after their initial release. In the case of Saudi Arabia, soft data such as market sentiments and survey-based indicators can sometimes be far away from reality. Thus, the challenge is how to extract the right piece of information from a large amount of noisy data.

Like in many other countries, GDP data in Saudi Arabia are published with lags and subject to substantial revisions. In fact, the initial quarterly GDP data are published with roughly 12 weeks lag. ${ }^{1}$ To overcome the issue of lacking timeliness, policymakers and investors have traditionally been using a number of relatively high-frequency indicators to assess the state of the economy. Examples of such indicators include Purchasing Managers' Index (PMI), cement production, electricity consumption, labor market data, real estate developments, performance of TASI, letters of credit, point of sale transactions, cash withdrawals from ATMs, automobile sales, and so on. While these indicators are to some extent useful, they often tend to provide mixed inferences about the state of the economy. Notably, drawing inference about economic activity in the Kingdom by examining soft and hard data prove to be difficult. This in part explains the wide differences in GDP projections by professional forecasters, some of whom rely mainly on judgment.

Saudi Arabia has embarked on an overarching reform agenda underpinned by Vision 2030 and its Vision Realization Programs (VRPs) to diversify the economy and further improve living standards for citizens. Within these programs, many initiatives and targets were put in place to ensure effective implementation. Moreover, the government has launched the National Center for Performance Measurement, known as "Adaa". One of the key mandates of this center is to track the progress made by public sector entities in achieving Vision targets. However, Adaa is not responsible for providing real-time

1 To view the release dates for the quarterly national accounts, visit GASTAT website at https://www.stats.gov.sa/en/dates. 
monitoring of the "state" of the economy. Given that VRPs are affecting a large number of industries and sectors, including untapped sectors that have huge growth potential, monitoring macroeconomic conditions in real time is of particular importance to help make the right policy and investment decisions, especially during this transformational period. In some respects, the growth model in the Kingdom is increasingly moving away from the public sector towards achieving higher private sector-led growth, where improving job creation and investment opportunities are two main goals to ensure a thriving private sector. Clearly, monitoring macroeconomic conditions of the non-oil sector in real time is extremely important to ensure well-informed policy and investment decision-making.

Against this background, the key objective of this paper is to provide a reliable tool for monitoring economic activity in real-time that can be used as a basis for making informed policy and investment decisions by policymakers and investors respectively. In econometrics, this tool is called "Nowcasting". ${ }^{2}$ In particular, nowcasting is the method used to assess GDP growth in the current quarter and usually within 3-4 months prior to the official publication of the quarterly national income account. By relying on nowcasting techniques, forecasters can monitor the state of the economy in real time by simply tracking a large set of soft and hard indicators as they emerge. Nowcasts are produced in many countries worldwide, both in advanced economies as well as in emerging markets economies (EMEs). ${ }^{3}$

In order to construct the nowcast measure of real GDP for Saudi Arabia, we apply the Generalized Dynamic Factor Model (GDFM), which is proven to perform well even if the number of variables $(\mathrm{N})$ is larger than the number of observations $(\mathrm{T})$. Since the main objective of this paper is to introduce the nowcasting concept to Saudi Arabia GDP, the paper purposely refrains from comparing nowcasting estimates obtained by GDFM with the other available methodologies. Instead, the paper only compares the GDFM estimates with standard Autoregressive model and Naïve Model, which is a simple four quarter

\footnotetext{
${ }^{2}$ Broadly speaking, the nowcasting term is used in meteorology to provide weather forecast in the present (or near present) time. See Banbura, Marta, et al. (2013) and Bok, Brandyn, et al. (2018) for more information. ${ }^{3}$ See for instance Aastveit and Trovik (2012), Arnoštová et al. (2011), Mariano and Murasawa (2003), and Giannone et al. (2008).
} 
moving average. Indeed, the nowcasting literature has shown that using GDFM to generate nowcasts has performed well in many countries [See Forni, Mario, et al. (2001) for more details]. ${ }^{4}$

The remainder of this paper is organized as follows: Section 2 gives a brief overview of the Generalized Dynamic Factor Model, Section 3 describes the data used to generate GDP nowcasts, Section 4 constructs real GDP nowcasts for Saudi Arabia, and Section 5 concludes the paper.

\section{Methodology}

We use the Generalized Dynamic Factor Model (GDFM) introduced by Altissimo, Cristadoro, Forni, Lippi, and Veronese (2010) and further developed by Alkhareif and Barnett (2013). Notably, this paper follows closely the estimation procedure provided by Alkhareif and Barnett (2013, a2015) by relying heavily on the principal component analysis and frequency domain methods. Our model assumes that each variable in the database $x_{i, t}$ has two unobservable, stationary, mutually orthogonal, components known as the common component $\chi_{i t}$ and the idiosyncratic component $\xi_{i t}$. Mathematically, the common component is written as the linear combination of the common shocks:

$$
\chi_{i t}=b_{i 1}(L) u_{1 t}+b_{i 2}(L) u_{2 t}+\cdots+b_{i q}(L) u_{q t}
$$

where $u_{j t}(j=1, \ldots, q)$ is the $j^{t h}$ common shock and $b(L)_{j t}$ is the $j^{\text {th }}$ coefficient with $L$ being the lag operator. The static representation form of the common components can be written as:

$$
\chi_{i t}=c_{i 1} F_{1 t}+c_{i 2} F_{2 t}+\cdots+c_{i r} F_{r t}
$$

where $F_{j t}(j=1, \ldots, r)$ is the $j^{t h}$ static factor and $c_{j t}$ is its corresponding factor loading. We can estimate the factors as linear combinations of the observable variables by forming

\footnotetext{
${ }^{4}$ Future research can undertake a comparison analysis of the different forecasting and nowcasting models to assess their usefulness to the Kingdom.
} 
a set of $r$ variables to form a basis for the linear space. In particular, we estimate the factors as the generalized principal components of the observed variables. Here, we use the contemporaneous variance-covariance matrices of the common and idiosyncratic components. As higlighted by Alkhareif and Barnett (2013), we overcome the issue associated with end-of-sample bias by relying only on the contemporaneous values of our indicators under examination. ${ }^{5}$

It is worth mentioning that the GDFM used in this paper exploit principal component analysis and frequency domain methods, whereby our dataset can be easly transfomed from time domain into frequency domain through proper Fourier transformation procedure. Precisely, let $\mathbf{x}_{t}=\left(x_{1 t}, \ldots, x_{n t}\right)^{\prime}, t \in \mathbb{Z}$, be a vector of our observable indicators and $\hat{\Sigma}_{x}(k)$ be the sample covariance matrix with lags $k=$ $-M, \ldots, M$. We estimate the spectral density matrix of the sample indicators by applying a discrete-time Fourier transformation to $\hat{\Sigma}_{x}(k)$ such as: 6

$$
\hat{S}_{x}\left(\theta_{j}\right)=\frac{1}{2 \pi} \sum_{k=-M}^{M} W_{k} \widehat{\Sigma}_{x}(k) e^{-i \theta_{j} k}
$$

where $W_{k}=1-\frac{|k|}{M+1}$ and $\theta_{j}=\frac{2 \pi j}{2 M+1}, j=-\mathrm{M}, \ldots, \mathrm{M}$.

We perform the dynamic principal component decomposition in order to decompose the spectral density matrices of the common and idiosyncratic components. In particular, we compute the eigenvalues $\lambda_{j}(\theta)$ and eigenvectors $U_{j}(\theta)$ of $\hat{S}_{x}\left(\theta_{j}\right)$, where we sort the eigenvalues in a decreasing order and accordingly rearrange the corresponding eigenvectors. Next, we apply the statistical technique proposed by Hallin and Liska (2007) to estimate the number of common factors $q$. Here, we set the number of dynamic factors

\footnotetext{
${ }^{5}$ See Altissimo, Cristadoro, Forni, Lippi, and Veronese (2010) for more information about the band pass filters used to extract the components. See Engle (1974) for more details about the frequency domain filtering approaches.

${ }^{6}$ Here, $J$ represents the number of points where the spectrum $\hat{S}_{x}\left(\theta_{j}\right)$ is estimated. In line with Forni et al. (2005), we set $M=\left[T^{\frac{1}{3}}\right]+1$. Thus, we have $M=6$. See Forni, Hallin, Lippi, and Reichlin (2000) and Hallin and Liska (2007) for additional information about the options to determine the size of Bartlett lag window.
} 
$q=3$ and number of static factors $r=6$. We construct the $(q \times q)$ matrix $\Lambda(\theta)$ containing the largest eigenvalues $\lambda_{1}(\theta), \ldots, \lambda_{q}(\theta)$ on its diagonal and the $(n \times q)$ matrix $U(\theta)$ of the corresponding eigenvectors. The spectral density matrix of the common component is given by: ${ }^{7}$

$$
\hat{S}()=U()() \tilde{U}()
$$

The spectral density matrix of the idiosyncratic component $\hat{S}_{\xi}\left(\theta_{j}\right)$ can therefore be obtained by subtracting $\hat{S}_{\chi}\left(\theta_{j}\right)$ from $\hat{S}_{x}\left(\theta_{j}\right)$. Next, we use the inverse discrete Fourier transformation to obtain the covariance matrixes of the common components $\hat{\Sigma}_{\chi}$ and idiosyncratic components $\widehat{\Sigma}_{\xi}$, respectively:

$$
\begin{gathered}
\hat{\Sigma}_{\chi}=\frac{2 \pi}{2 J+1} \sum_{j=-J}^{J} \hat{S}_{\chi}\left(\theta_{j}\right) \\
\hat{\Sigma}_{\xi}=\frac{2 \pi}{2 J+1} \sum_{j=-J}^{J} \hat{S}_{\xi}\left(\theta_{j}\right)
\end{gathered}
$$

We derive the generalized eigenvectors $\mathbf{v}_{k}$ and eigenvalues $\lambda_{k}$ of the pair of matrices $\left(\hat{\Sigma}_{\chi}, \hat{\Sigma}_{\xi}\right)$ that solve the generalized eigenvalue problem: ${ }^{8}$

$$
\widehat{\Sigma}_{\chi} \mathbf{v}_{k}=\lambda_{k}\left(\hat{\Sigma}_{\xi}\right) \mathbf{v}_{k}
$$

with the normalization condition $\mathbf{v}_{k}^{\prime}\left(\widehat{\Sigma}_{\xi}\right) \mathbf{v}_{k}=1$. Here, we order the eigenvalues from largets to lowerst and rearragne the corresponding eigenvectors accordingly. The generalized principal components can be defined as: ${ }^{9}$

\footnotetext{
${ }^{7}$ Note that the tilde represents the complex conjugation.

${ }^{8}$ See Alkhareif and Barnett (2013), Cristadoro, Saporito, and Venditti (2013) for more details and see Cristadoro, Forni, Reichlin, and Veronese (2005) for an alternative representation of the generalized eigenvalue problem.

${ }^{9}$ See Forni et al. (2011) and Alkhareif and Barnett (2013) for more details about the estimation procedure and treatment of end-of-sample bias associated with standard band pass filters.
} 


$$
w_{k t}=\mathbf{v}_{k}^{\prime} \mathbf{x}_{t}, \quad \text { for } k=1, \cdots, r
$$

Estimating the common component is now straightforward. Let $\mathbf{V}=\left(\mathbf{v}_{1} \cdots \mathbf{v}_{r}\right)$ be a $(n \times r)$ matrix of the generalized eigenvectors. In line with Alkhareif and Barnett (2013), let $\mathbf{w}_{t}=\left(w_{1 t} \cdots w_{r t}\right)^{\prime}=\mathbf{V}^{\prime} \mathbf{x}_{t}$ be the column vector of the first $r$ generalized principal components. The estimation of the common component is therefore given by:

$$
\widehat{\chi_{t}}=\widehat{\Sigma}_{\chi} \mathbf{V}\left(\mathbf{V}^{\prime} \widehat{\Sigma}_{x} \mathbf{V}\right)^{-1} \boldsymbol{w}_{t}
$$

\section{Data Descriptions and Sources}

The estimation analysis of this paper is based on a panel of macroeconomic and financial indicators for the Saudi economy. In total, the paper uses a panel of 272 crosssectional series in order to nowcast GDP. The span of the panel is from January 2010 to June 2018. To construct our GDP nowcasts, we set the quarterly real GDP as our target variable. In particular, data from January 2015 onwards are reserved in order to generate our GDP nowcasts. Here, it is worth mentioning that the relatively short period of our dataset is mainly due to the limited number of observations available for quarterly GDP, which is officially published starting from 2010. In order to convert quarterly GDP into monthly series, one can apply the approximation method proposed by Mariano and Murasawa (2003). For simplicity, we decided to initially assign the values of the observed quarterly GDP into their corresponding unobserved monthly GDP and update the series with the computed nowcasts.

The data were collected from various sources such as the General Authority for Statistics (GASTAT), Saudi Arabian Monetary Authority (SAMA), Organization of the Petroleum Exporting Countries (OPEC), Bank of International Settlements (BIS), Bloomberg database, the International Monetary Fund (IMF), and the Federal Reserve Economic Database (FRED). Our dataset uses indicators from domestic demand, trade, surveys, and monetary and financial variables. Such indicators include the non-oil Purchasing Managers' Index (PMI), cement production, electricity consumption, automobile sales, public sector data, performance of TASI, letters of credit, commodity 
prices, crude oil production, natural gas and refinery's production, exchange rates (i.e., NEER and REER), interest rates (e.g., 3M SAIBOR), point of sale transactions, and cash withdrawals from ATMs.

In line with the analysis provided by Alkhareif and Barnett (2013), we apply proper transformations to ensure stationarity of all variables in the dataset. The seasonal series are adjusted using X13 procedure. We also applied moving average interpolation whenever we encountered missing data. Since we had a total of 272 variables in our study, including the results of the standard unit root tests was not feasible. The overall results of the unit root tests can be provided upon request.

\section{Nowcasting Real GDP for Saudi Arabia}

To nowcast GDP in Saudi Arabia, it is useful to look at the oil sector GDP and nonoil sector GDP separately, given the distinct nature of both sectors. Notably, the real oil sector GDP is highly influenced by movements in crude oil production, natural gas and refineries' production. Figure 1 shows that the growth rate of the oil sector GDP is highly influenced by movements in oil production. Indeed, Saudi authorities can easily nowcast oil sector GDP by focusing mainly on the data from the production levels of the crude oil, natural gas, and refined products, which are available in a timely manner. ${ }^{10}$ During 2017 , the gap between growth rates of oil production and oil sector GDP widened the most on the back of stronger production in the refining industry. In June 2018, Saudi Arabia increased its oil production by around 400tbpd and OPEC has agreed with other oilproducing countries to raise oil output. Therefore, we expect the oil sector GDP to grow by about 1.6 percent in 2018 Q2 (Figure1). By the same token, the oil sector GDP is expected to grow by around 3 percent in 2018. ${ }^{11}$ Because of its simplicity and timeliness, we will use crude oil production as our nowcasting tool only for the oil sector GDP.

\footnotetext{
${ }^{10}$ See Alkhareif et. al (2017) for more analysis on oil and non-oil GDP in Saudi Arabia.

${ }^{11}$ It is worth mentioning that the actual data published by GSTAT showed that the oil sector GDP grew by 3 percent in 2018 .
} 
Figure 1: Real Oil-Sector GDP Growth and Oil Production (2012: Q2 to 2018: Q2)

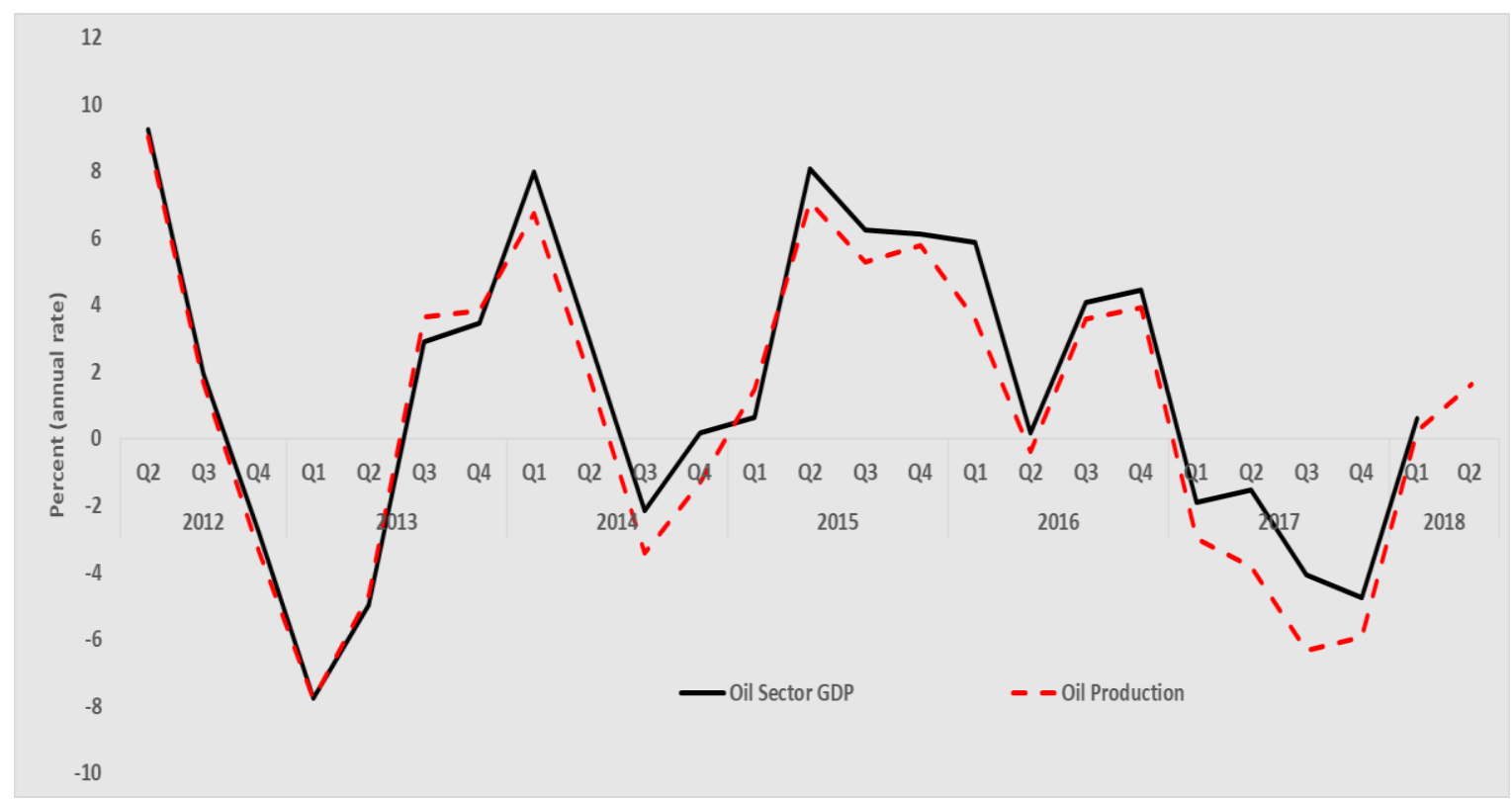

Source: GASTAT and author calculations.

Nowcasting economic activity in the non-oil sector is less straightforward, as there are a large number of factors (both common and idiosyncratic) that affect investment and consumption levels. In this context, the paper provides breakdown of the non-oil sector GDP nowcasts by institutional sectors in accordance with the GSTAT classification (i.e., non-oil sector comprises both the public and private sectors). In our view, the non-oil private sector GDP nowcasts provided in this paper can substitute the traditional set of indicators used to monitor the monthly private sector activity, including inter alia the PMI, point of sale transactions, cash withdrawals from ATMs, cement production, and electricity consumption. 
The analysis of this paper is based on monthly indicators for the period from January 2010 to June 2018, while GDP is the only variable with quarterly series. We carry out a pseudo real time out-of-sample exercise for the period from January 2015 to March 2018. In other word, we estimate the model recursively starting with the first sample period of January 2010 to December 2014. As new data arrive, we subsequently add them to the database and reestimate our model to generate new forecasts. We continue this exercise until we reach the end point of our data interval. In addition, we provide 2018 Q2 nowcasts for GDP by utilizing the available monthly economic and financial indicators available until end-June 2018.

Figures 2-5 compare the annual growth rates of the actual GDP with the GDP nowcasts over the period from January 2015 to March 2018. Clearly, the GDP nowcasts seem to track the movements of GDP very closely. Thus, nowcasts can provide a timely assessment about the overall performance of the Saudi economy. Therefore, using these nowcasts can, in our view, help policymakers to make timely and well-informed decisions that could contribute to smoothing the fluctuations of the business cycle. 
The paper also provides GDP nowcasts for the Saudi economy in 2018 Q2. As shown in Figures 2-5, we expect the overall GDP to grow by 1.9 percent in Q2 on the back of favorable economic conditions and ongoing structural reforms underpinned by Vision 2030 and its VRPs. ${ }^{12}$ The non-oil sector GDP is expected to grow by 2.1 percent in Q2, where the private and government sectors are projected to increase by 1.5 percent and 3.8 percent respectively. ${ }^{13}$ In our view, the pickup in non-oil sector growth rate reflects confluence of factors, including stronger government spending (which grew by 26 percent in the first half of 2018), the successful rollout of the Privatization Program and the Financial Sector Development Program, and the recent inclusion in the FTSE Russell and MSCI EM indices. ${ }^{14}$ Indeed, the firming up of oil price has strengthened the fiscal position of the country and improved market sentiment, as it can be seen from the strong performance of TASI, which has grown by around 17 percent during the first half of 2018.

\section{Figure 2: Real Overall GDP Growth and GDFM Nowcast (2015: Q1 to 2018: Q2)}

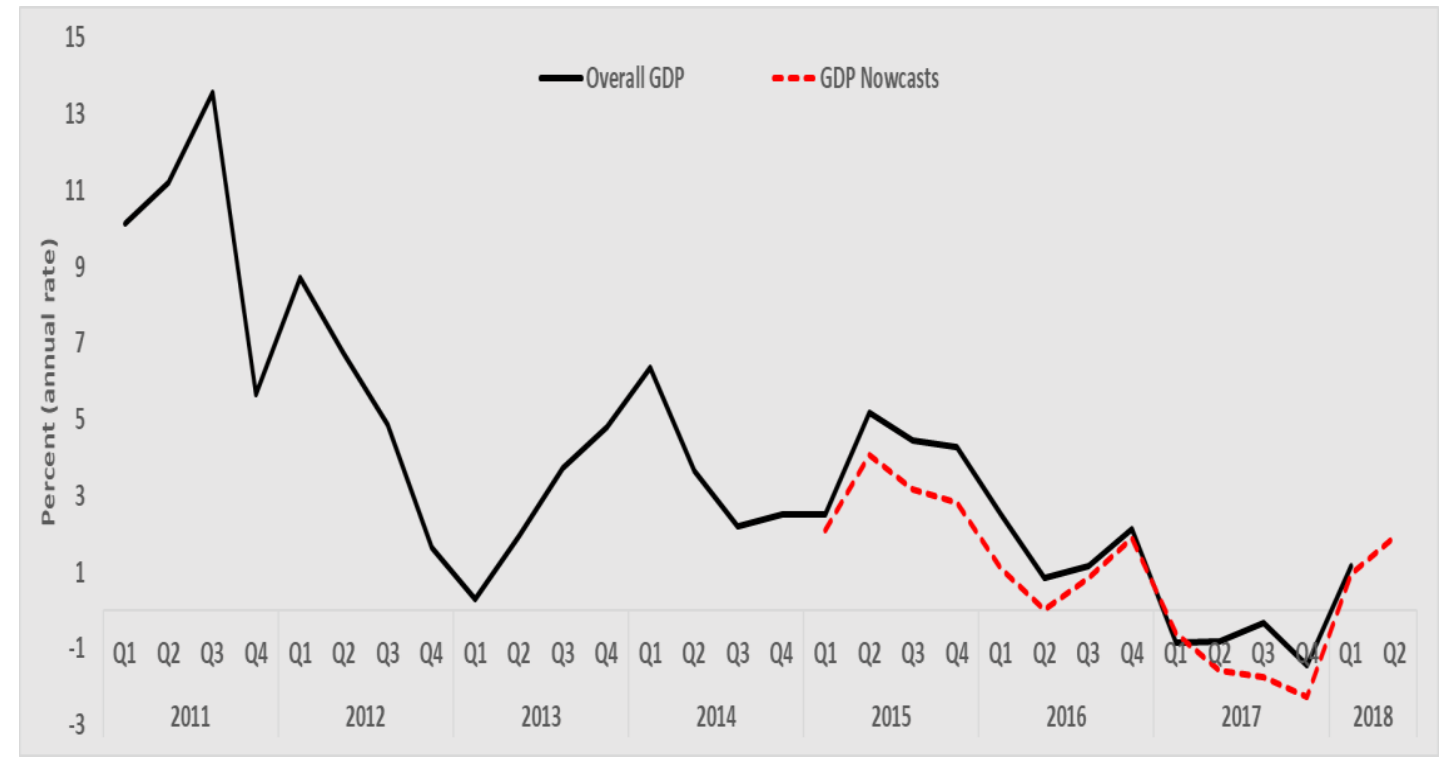

Source: GASTAT and author calculations.

\footnotetext{
12 The actual data published by GSTAT showed that the overall GDP to grew by 1.6 percent in Q2, which is very close to our estimates.

${ }^{13}$ Similarly, the actual data published by GSTAT showed that the non-oil sector GDP to grew by 2.5 percent in Q2, within which the private and government sectors grew by 1.9 percent and 3.8 percent respectively. This is extremely close to our estimates.

${ }^{14}$ More recently, the S\&P Dow Jones has made the announcement to upgrade the Saudi equity market to emerging market status starting next year.
} 
Figure 3: Real Non-Oil-Sector GDP Growth and GDFM Nowcast (2015: Q1 to 2018: Q2)

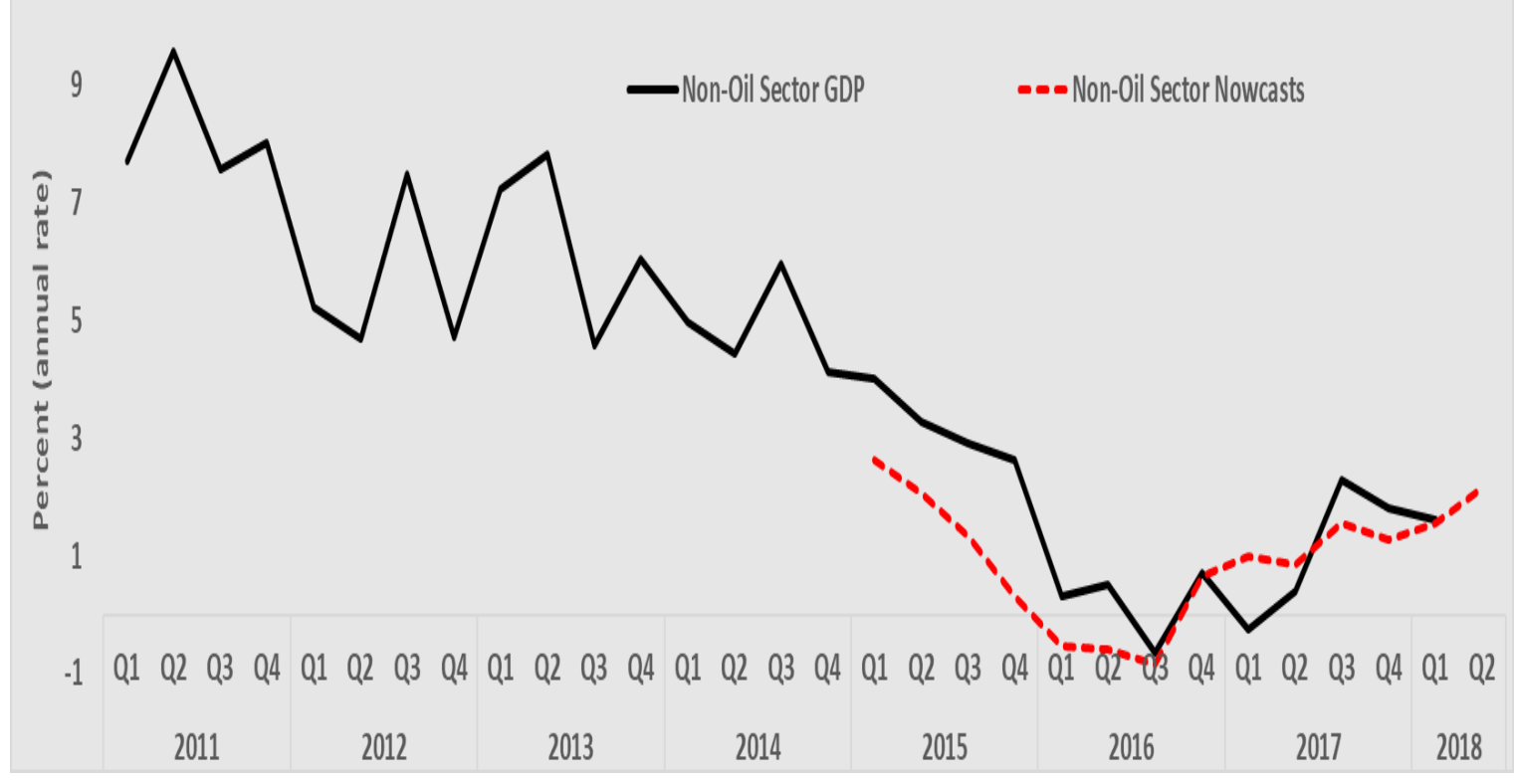

Source: GASTAT and author calculations.

Figure 4: Real Private Sector GDP Growth and GDFM Nowcast (2015: Q1 to 2018: Q2)

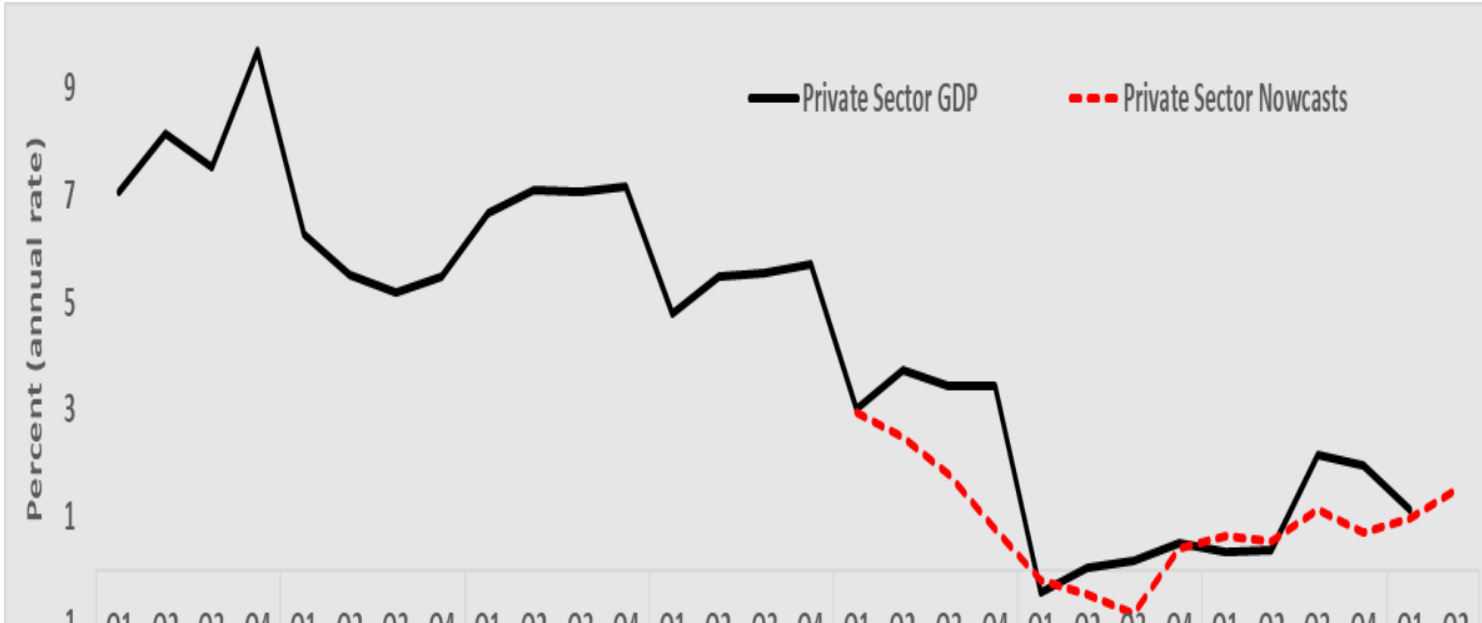

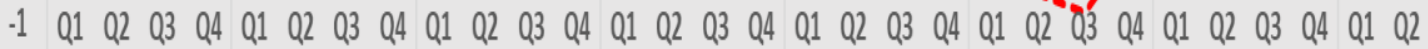

$\begin{array}{llllllll}2011 & 2012 & 2013 & 2014 & 2015 & 2016 & 2017 & 2018\end{array}$

Source: GASTAT and author calculations. 
Figure 5: Real Government Sector GDP Growth and GDFM Nowcast (2015: Q1 to 2018: Q2)

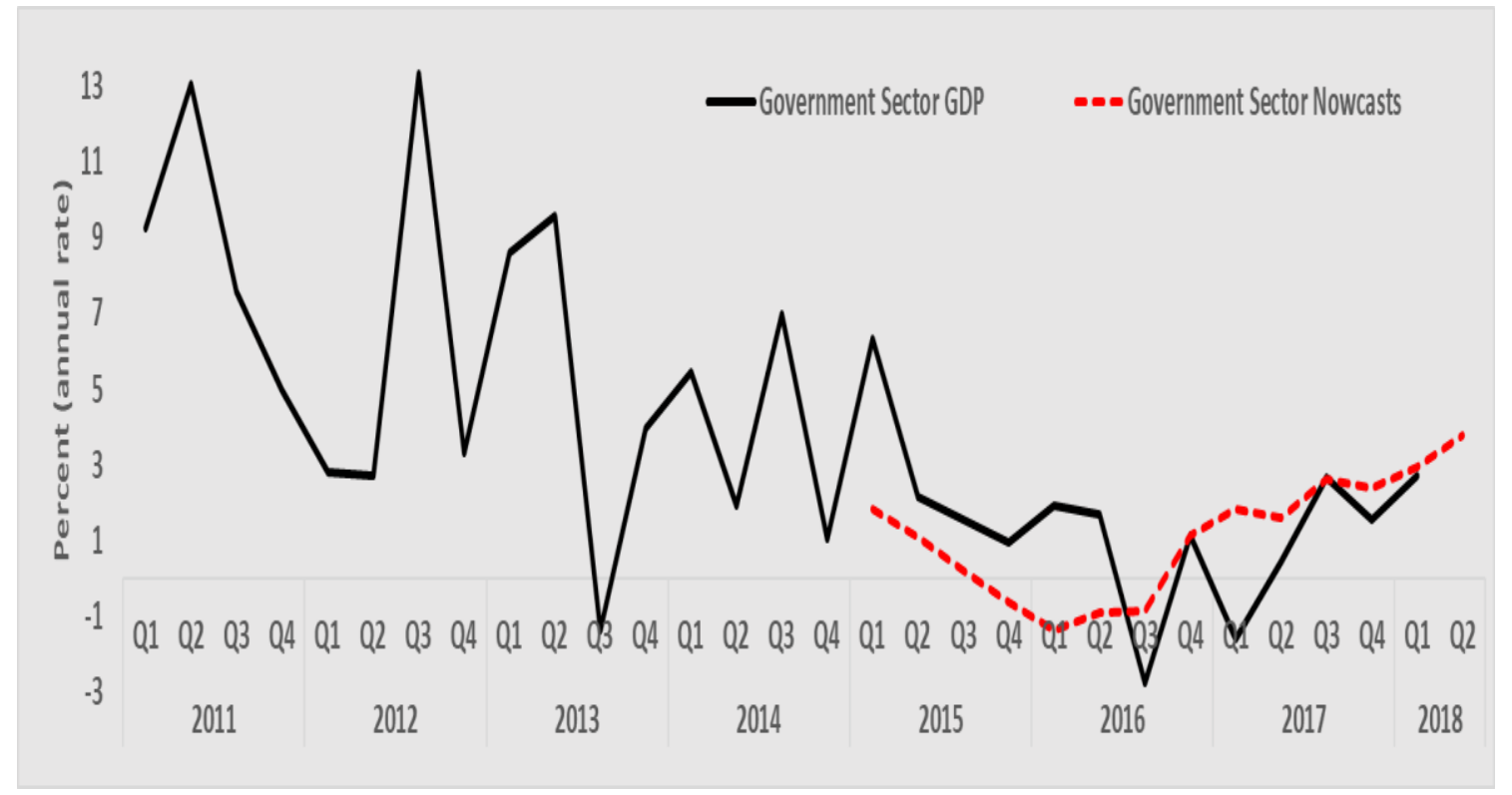

Source: GASTAT and author calculations.

Table 1 provides short summary statistics of the GDP indicators and GDP estimates derived from GDFM, Autoregressive model, and Naïve Model, which is a simple four quarter moving average, as indicated earlier. The sample period spans from January 2015 to March 2018. Broadly speaking, the behavior of our GDFM nowcasts are closely linked to those of the official GDP indicators, including for the non-oil sector. Moreover, the GDP nowcasts derived from GDFM are highly correlated with the official GDP indicators, except for the government sector. Overall, the GDFM seems to yield better results compared with the other two models. 
Next, we evaluate the accuracy of our GDP nowcasts using the Root Mean Squared Error (RMSE) over the sample period from 2016 Q4 to 2018 Q1. In particular, we compare our GDFM nowcasts with both the Autoregressive model and the Naïve Model. Table 2 reports the RMSE outcomes of the different models across the GDP institutional sectors. The results confirm the superiority of GDFM over the other two models across all GDP indicators. Therefore, the paper demonstrates the usefulness of using GDFM in tracking real growth rates of GDP for Saudi Arabia.

Table 1: Descriptive Statistics of the GDP Indicators and Nowcasts (2015: Q1 to 2018: Q1)

\begin{tabular}{|c|c|c|c|c|c|c|}
\hline & & Mean & Max & Min & S.D. & Corr. with $G D P$ \\
\hline \multirow{4}{*}{$\begin{array}{c}\text { Overall } \\
\text { GDP }\end{array}$} & Actual & 1.6 & 5.2 & -1.4 & 2.2 & 1.0 \\
\hline & GDFM & 0.8 & 4.1 & -2.3 & 2.0 & 0.9 \\
\hline & AR (1) & 3.0 & 9.1 & 0.7 & 2.1 & 0.7 \\
\hline & Naïve & 2.6 & 4.2 & 0.0 & 1.5 & 0.6 \\
\hline \multirow{4}{*}{$\begin{array}{c}\text { Oil } \\
\text { Sector }\end{array}$} & Actual & 1.8 & 8.1 & -4.7 & 4.2 & 1.0 \\
\hline & GDFM & 0.9 & 7.1 & -6.3 & 4.5 & 0.9 \\
\hline & AR (1) & 2.6 & 10.9 & -3.6 & 2.9 & 0.4 \\
\hline & Naïve & 2.9 & 6.6 & -0.8 & 2.0 & 0.1 \\
\hline \multirow{4}{*}{$\begin{array}{l}\text { Non-oil } \\
\text { Sector }\end{array}$} & Actual & 1.5 & 4.0 & -0.6 & 1.5 & 1.0 \\
\hline & GDFM & 0.9 & 2.6 & -0.8 & 1.0 & 0.8 \\
\hline & $\mathrm{AR}(1)$ & 3.2 & 7.0 & 0.1 & 1.9 & 0.8 \\
\hline & Naïve & 2.4 & 5.4 & 0.0 & 2.0 & 0.5 \\
\hline \multirow{4}{*}{$\begin{array}{l}\text { Private } \\
\text { Sector }\end{array}$} & Actual & 1.5 & 3.7 & -0.4 & 1.5 & 1.0 \\
\hline & GDFM & 0.8 & 2.9 & -0.8 & 1.1 & 0.8 \\
\hline & AR (1) & 3.0 & 6.2 & 0.4 & 1.6 & 0.7 \\
\hline & Naïve & 2.7 & 5.7 & 0.1 & 2.1 & 0.5 \\
\hline \multirow{4}{*}{$\begin{array}{c}\text { Government } \\
\text { Sector }\end{array}$} & Actual & 1.4 & 6.3 & -2.8 & 2.2 & 1.0 \\
\hline & GDFM & 0.9 & 2.9 & -1.4 & 1.5 & 0.3 \\
\hline & AR (1) & 1.9 & 3.7 & 0.7 & 0.7 & 0.1 \\
\hline & Naïve & 2.0 & 4.6 & -0.7 & 1.8 & 0.4 \\
\hline
\end{tabular}

Source: GASTAT and author calculations. 
Table 2: Root Mean Squared Error (2016: Q4 - 2018: Q1)

\begin{tabular}{lccccc}
\hline \hline & $\begin{array}{c}\text { Overall } \\
\text { GDP }\end{array}$ & Oil Sector & Non-oil Sector & Private Sector & Government Sector \\
\cline { 2 - 6 } AR (1) & 0.029 & 0.059 & 0.023 & 0.021 & 0.039 \\
GDFM & $\mathbf{0 . 0 0 9}$ & $\mathbf{0 . 0 1 7}$ & $\mathbf{0 . 0 1 0}$ & $\mathbf{0 . 0 1 0}$ & $\mathbf{0 . 0 2 0}$ \\
Naïve & 0.043 & 0.099 & 0.026 & 0.021 & 0.046 \\
\hline $\begin{array}{l}\text { Note: AR: Autoregressive model, GDFM: Generalized Dynamic factor model, Naïve Model: Four quarter moving average. The reported } \\
\text { numbers are the RMSE averages over the sample period from 2016: Q4 to 2018: Q1. Finally, the numbers in bold indicate that the model } \\
\text { has the lowest RMSE. }\end{array}$
\end{tabular}

To conclude, future studies can compare between alternative nowcasting measures to assess their usefulness to the case of Saudi Arabia, similar to the comparison exercise carried out by Jansen, Jin and De Winter (2016) for the euro area. Going forward, we see merit in exploring the benefits of utilizing big data analysis and machine learning techniques to obtain real-time assessment about the state of the economy. A large number of studies have also shown the usefulness of applying advanced monetary indicators (known as Divisia indices) to help predict business cycles. Future studies can assess weather using Divisia indices can help predict GDP growth in Saudi Arabia [Alkhareif and Barnett (2013 and a2015)]. ${ }^{15}$

\section{Conclusion}

A large number of major central banks, government agencies, investment banks worldwide use GDP nowcasts publicly or internally. Since Saudi Arabia has the largest economy in the MENA region and its capital market, which is also the largest in the Arab region, is increasingly attracting foreign investments particularly after its inclusion in the FTSE Russell and MSCI EM indices, providing GDP nowcasts of Saudi Arabia is beneficial for policymakers, investors, and academics alike.

\footnotetext{
${ }^{15}$ For more insights about the applications of Divisia indexes in the case of Saudi Arabia, see Alkhareif and Barnett (b2015).
} 
The paper develops monthly GDP nowcasts for Saudi Arabia by applying a Generalized Dynamic Factor Model (GDFM) on a panel of 272 variables over the period from January 2010 to June 2018. Specifically, the paper provides breakdown of GDP nowcasts by institutional sectors in accordance with the GSTAT classification (i.e., oil sector and non-oil sector). The findings of the paper confirm the usefulness of GDFM in providing reliable GDP nowcasts for the Saudi economy, since our nowcasts can accurately mimic GDP growth rates for Saudi Arabia very well, including for the non-oil sector. In our view, the non-oil private sector GDP nowcasts provided in this paper can substitute the traditional set of indicators used to monitor the monthly private sector activity. Finally, our GDFM has outperformed the Autoregressive model and the Naïve Model in describing the business cycle in Saudi Arabia, including during the economic transformation period that was launched in early 2016. 


\section{References}

Aastveit, Knut Are, and Tørres Trovik (2012), "Nowcasting Norwegian GDP: The role of asset prices in a small open economy." Empirical Economics 42, no. 1: 95-119.

Alkhareif, Ryadh M., William A. Barnett, and Nayef A. Alsadoun (2017), "Estimating the Output Gap for Saudi Arabia." International Journal of Economics and Finance 9, no. 3: 81 .

Alkhareif, Ryadh M., and William A. Barnett (a2015), "Core inflation indicators for Saudi Arabia." Panoeconomicus 62, no. 3: 257-266.

Altissimo, Filippo, Riccardo Cristadoro, Mario Forni, Marco Lippi, and Giovanni Veronese (2010), "New Eurocoin: tracking economic growth in real time." The Review of Economics and Statistics 92, no. 4: 1024-1034.

Arnoštová, Kateřina, David Havrlant, Luboš Růžička, and Peter Tóth (2011), "Short-term forecasting of Czech quarterly GDP using monthly indicators." Finance a úvěr (Czech Journal of Economics and Finance) 61, no. 6: 566-583.

Banbura, Marta, Domenico Giannone, Michele Modugno, and Lucrezia Reichlin (2013), Now-casting and the real-time data flow. Handbook of economic forecasting 2, no. Part A: 195-237.

Barnett, William A., and Ryadh M. Alkhareif. Advances in Monetary Policy Design: Applications to the Gulf Monetary Union (2013), Cambridge Scholars Publishing.

Barnett, William A., and Ryadh M. Alkhareif (b2015), "Modern and traditional methods for measuring money supply: the case of Saudi Arabia." International Journal of Financial Studies 3, no. 1: 49-55.

Bok, Brandyn, Daniele Caratelli, Domenico Giannone, Argia M. Sbordone, and Andrea Tambalotti (2018), "Macroeconomic nowcasting and forecasting with big data." Annual Review of Economics 0.

Cristadoro, Riccardo, Giuseppe Saporito, and Fabrizio Venditti (2013), "Forecasting inflation and tracking monetary policy in the euro area: does national information help?" Empirical Economics 44, no. 3: 1065-1086.

Cristadoro, Riccardo, Mario Forni, Lucrezia Reichlin, and Giovanni Veronese (2005), "A core inflation indicator for the euro area." Journal of Money, Credit and Banking: 539-560. 
Engle, Robert F (1974), "Band spectrum regression." International Economic Review: 111.

Forni, Mario, Marc Hallin, Marco Lippi, and Lucrezia Reichlin (2000), "The generalized dynamic-factor model: Identification and estimation." Review of Economics and statistics 82, no. 4: 540-554.

Forni, Mario, Marc Hallin, Marco Lippi, and Lucrezia Reichlin (2001), "Coincident and leading indicators for the Euro area." The Economic Journal 111, no. 471: 62-85.

Forni, Mario, Marc Hallin, Marco Lippi, and Lucrezia Reichlin (2005), "The generalized dynamic factor model: one-sided estimation and forecasting." Journal of the American Statistical Association 100, no. 471: 830-840.

Forni, Mario, and Marco Lippi (2011), "The general dynamic factor model: One-sided representation results." Journal of Econometrics 163, no. 1: 23-28.

Giannone, Domenico, Lucrezia Reichlin, and David Small (2008), "Nowcasting: The realtime informational content of macroeconomic data." Journal of Monetary Economics 55, no. 4: 665-676.

Hallin, Marc, and Roman Liška (2007), "Determining the number of factors in the general dynamic factor model." Journal of the American Statistical Association 102, no. 478: 603-617.

Jansen, W. Jos, Xiaowen Jin, and Jasper M. de Winter (2016), "Forecasting and nowcasting real GDP: comparing statistical models and subjective forecasts." International Journal of Forecasting 32, no. 2: 411-436.

Mariano, Roberto S., and Yasutomo Murasawa (2003), "A new coincident index of business cycles based on monthly and quarterly series." Journal of applied Econometrics 18, no. 4: 427-443.

Stock, James H., and Mark Watson (2011), "Dynamic factor models." Oxford handbook on economic forecasting. 